\title{
PROFIL HEMATOLOGI PADA SINDROM KORONER AKUT
}

\author{
${ }^{1}$ Albert Benedictus Sirait \\ ${ }^{2}$ Linda W. A. Rotty \\ ${ }^{2}$ A. Lucia Panda
}

\author{
${ }^{1}$ Kandidat Skripsi Fakultas Kedokteran Universitas Sam Ratulangi Manado \\ ${ }^{2}$ Bagian Ilmu Penyakit Dalam Fakultas Kedokteran Universitas Sam Ratulangi Manado \\ Email: albertsirait10_131@yahoo.com
}

\begin{abstract}
One of cardiovascular disease is syndrome coronary acute. Syndrome coronary acute divided into three groups, they are unstable angina pectoris (UAP), non-ST segment elevation myocardial infarction (NSTEMI), ST segment elevation myocardial infarction (STEMI). Besides the changes of cardiac biomarkers profile, the patient's hematologic profile will also experience changes. This study's aim to determine hematologic profile of syndrome coronary acute and included the profiles of hemoglobin, leukocyte, thrombocyte, hemaocrit, MCV, MCH, and MCHC. The method of this study was analytic with cross-sectional approach and using secondary data, medical report. The samples were all patients that take hospitalization care in BLU RSUP Prof. Dr. R. D. Kandou Manado and diagnosed with syndrome coronary acute in January 2012 to December 2012. The result showed more patient likely to have lower hemoglobin, normal leukocyte, normal thrombocyte, lower hematocrit, normal MCV, MCH, and MCHC. Conclusion: There were changes on hematologic profile even though leukocyte and thrombocye profile more likely found normal. The changes of hematologic profile can be used as basic prognosis for the patients in the future.
\end{abstract}

Keywords: Profile hematology, syndrome coronary acute.

Abstrak: Salah satu penyakit kardiovaskuler adalah sindrom koroner akut. Sindrom koroner akut dibagi menjadi tiga kelompok yaitu angina pektoris tidak stabil (UAP), infark miokard tanpa elevasi segmen ST (NSTEMI), dan infark miokard dengan elevasi segmen ST (STEMI). Selain terjadinya perubahan pada biomarker cedera jantung, profil hematologi pasien juga akan mengalami perubahan. Penelitian ini bertujuan untuk mengetahui profil hematologi pada sindrom koroner akut dan meliputi profil hemoglobin, leukosit, trombosit, hematokrit, MCV, $\mathrm{MCH}$, dan MCHC. Penelitian ini menggunakan metode analitik dengan pendekatan crosssectional dengan menggunakan data sekunder berupa rekam medis. Sampel dalam penelitian ini adalah semua pasien di BLU RSUP Prof. Dr. R. D. Kandou Manado yang dirawat inap dengan diagnosis sindrom koroner akut pada periode Januari 2012 sampai dengan Desember 2012. Hasil penelitian menunjukkan pasien cenderung lebih banyak pasien yang memiliki profil hemoglobin yang rendah, nilai leukosit yang normal, nilai trombosit normal, nilai hematokrit yang rendah, nilai MCV, MCH, dan MCHC yang normal. Kesimpulan: Terdapat perubahan pada profil hematologi meskipun pada profil leukosit dan trombosit cenderung lebih banyak pasien yang memiliki profil yang normal. Perubahan nilai profil hematologi pada pasien bisa dijadikan dasar prognosis bagi pasien kedepannya.

Kata kunci: profil hematologi, sindrom koroner akut.

Menurut data WHO tahun 2012, penyakit kardiovaskuler memiliki angka kematian sebesr 48\%. Salah satu penyakit kardiovaskuler adalah sindrom koroner akut. ${ }^{1}$ Sindrom koroner akut dibagi menjadi 3, yaitu: angina pektoris tidak stabil (UAP), miokard infark tanpa elevasi segmen ST 
(NSTEMI), dan miokard infark dengan elevasi gelombang ST (STEMI). ${ }^{2}$

Ketiganya sering memiliki keluhan awal yang sama, yaitu nyeri dada. Sehingga, diperlukan pemeriksaan marker untuk bisa segera mengetahui diagnosis. Pemeriksaan marker yang disarankan adalah pemeriksaan CK-MB dan troponin. ${ }^{3-7}$

Akan tetapi, selain terdapat perubahan pada marker yang sudah disebutkan profil hematologi pada darah juga berubah. Salah satu contohnya adalah meningkatnya trombosit. Hal ini dikarenakan adanya proses inflamasi yang ikut berperan dalam penyakit sindrom koroner akut. $^{2,3}$

Penelitian ini bertujuan untuk mengetahui profil hematologi pada sindrom koroner akut dan bagaimana hubungannya.

\section{METODE PENELITIAN}

Penelitian ini bersifat analitik retrospektif dengan menggunakan data sekunder berupa rekam medis pasien RSUP Prof. Dr. R. D. Kandou.

Data diambil dari BLU RSUP Prof. Dr. R. D. Kandou dan semuanya merupakan data dari bulan Januari 2012 sampai dengan Desember 2012. Sampel penelitian ini adalah semua pasien di RSUP Prof. Dr. R. D. Kandou yang dirawaat inap dengan diagnosis sindrom koroner akut.

Variabel yang digunakan adalah pasien sindrom koroner akut, umur, jenis kelamin, jumlah hemoglobin, leukosit, trombosit, hematokrit, MCV, MCH, dan MCHC.

Prosedur penelitian ini adalah mengambil data sekunder yaitu rekam medis dari RSUP Prof. Dr. R. D. Kandou kemudian dianalisis dan disajikan dalam bentuk tabel dan diagram persentase.

\section{HASIL DAN BAHASAN}

\section{Profil hemoglobin}

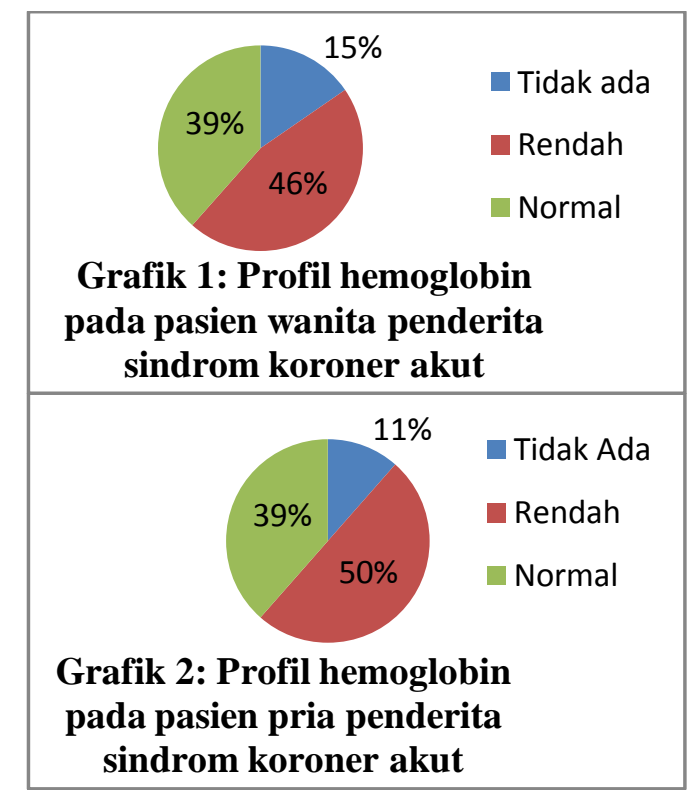

Berdasarkan hasil penelitian dan dibandingkan dengan standar yang diajukan oleh Hoffbrand, ditemukan lima wanita memiliki kadar hemoglobin normal, enam wanita memiliki kadar hemoglobin rendah dan ada dua data yang hilang/tidak ada data. Untuk pasien pria ditemukan sepuluh pria memiliki kadar hemoglobin normal, tiga belas pasien memiliki kada hemoglobin rendah dan ada tiga data yang hilang/tidak ada. ${ }^{8}$

Berdasarkan teori yang ditemukan, pasien dengan anemia yang kadar hemoglobinnya $\leq 10 \mathrm{~g} / \mathrm{dL}$ memiliki resiko kematian sebesar $21,6 \%{ }^{9}$

\section{Profil leukosit}

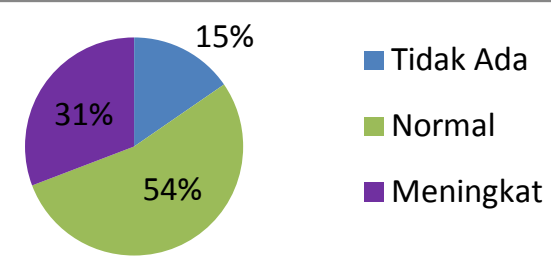

Grafik 3: Profil leukosit pada wanita penderita sindrom koroner akut 


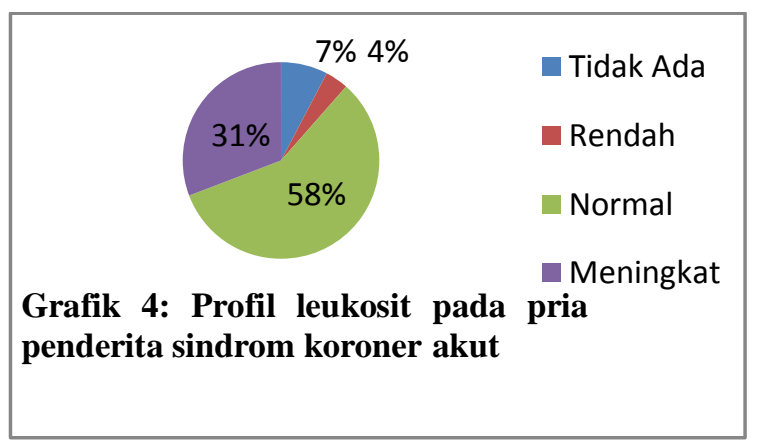

Berdasarkan hasil penelitian dan dibandingkan dengan standar yang diajukan hoffbrand, didapatkan total dua puluh dua pasien memiliki kadar leukosit normal, satu pasien memiliki kadar leukosit rendah, dan dua belas pasien dengan kadar yang meningkat. Ada empat data yang hilang/tidak ada. ${ }^{8}$

Berdasarkan teori yang ditemukan meningkatnya kadar leukosit adalah akibat leukosit merupakan salah satu komponen inflamasi dan peningkatan dari kadar leukosit ini bisa digunakan untuk memprediksi kemungkinan meninggalnya pasien akibat penyakit jantung koroner. ${ }^{10}$

\section{Profil trombosit}

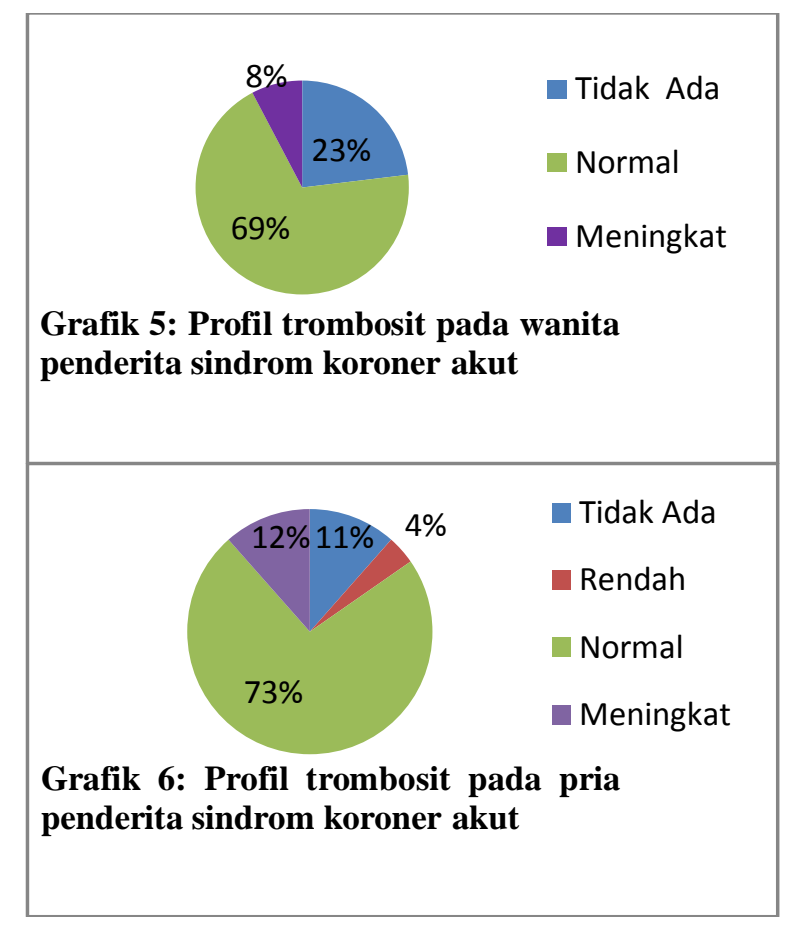

Untuk trombosit, berdasarkan hasil penelitian dan standar yang diajukan Michelson, ditemukan total dua puluh delapan pasien dengan kadar trombosit normal, satu dengan kadar trombosit rendah, empat pasien dengan kadar trombosit meningkat, dan enam data hilang/tidak ada. $^{11}$

Bila dibandingkan dengan teori, hasil temuan menunjukkan hal yang berbeda. Pasien sindrom koroner akut cenderung memiliki kadar trombosit meningkat dikarenakan dalam proses penyakitnya terlibat proses inflamasi dan agregasi trombosis. $^{12}$

\section{Profil hematokrit}

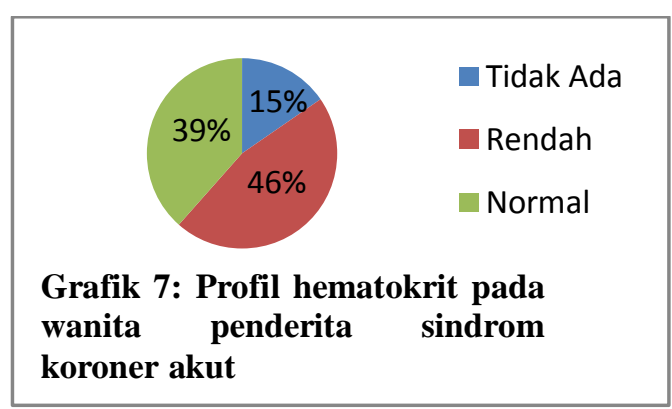

\begin{tabular}{|c|c|}
\hline $\begin{array}{l}\text { Grafik 8: Profil he } \\
\text { pria penderita sin } \\
\text { akut }\end{array}$ & $\begin{array}{l}\text { Tidak Ada } \\
\text { Rendah } \\
\text { Normal } \\
\text { Meningkat } \\
\text { pada } \\
\text { oner }\end{array}$ \\
\hline
\end{tabular}

Hasil temuan dan menurut standar hoffbrand, ditemukan pada wanita enam wanita dengan kadar hematokrit normal, enam pasien dengan kadar hematokrit rendah, dan dua yang data hilang/tidak ada. Pada pria ditemukan, delapan pasien dengan kadar hematokrit normal, empat belas dengan kadar hematokrit rendah, satu pasien dengan kadar hematokrit meningkat, dan tiga yang data hilang/tidak ada. ${ }^{8}$

Berdasarkan teori yang ada, nilai kadar hematokrit bisa dijadikan prediktor independen bagi CVD (cardiovascular death), IHD (ischaemic heart disease), dan non-CVD mortality. ${ }^{13}$ 
Profil MCV, MCH, MCHC

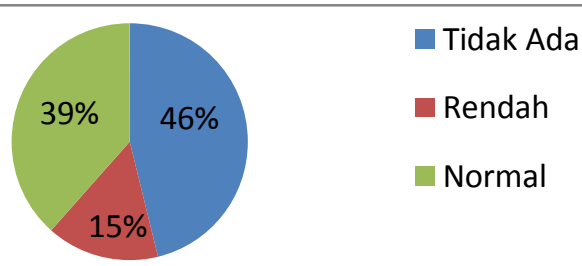

Grafik 9: Profil MCV pada wanita penderita sindrom koroner akut

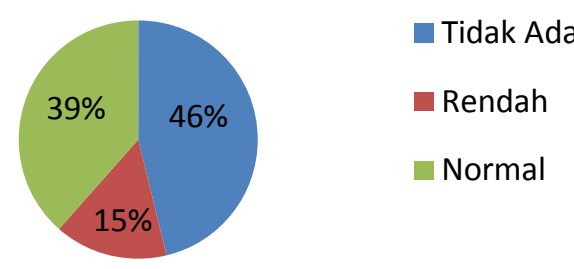

Grafik 10: Profil MCH pada wanita penderita sindrom koroner akut

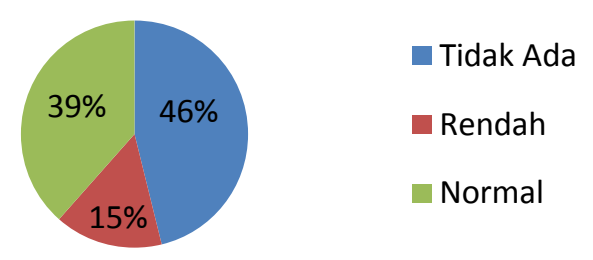

Grafik 11: Profil MCHC pada wanita penderita sindrom koroner akut

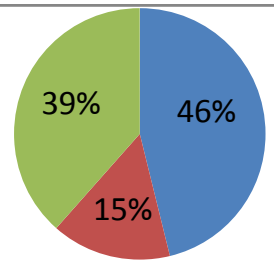

- Tidak Ada

- Rendah

Normal

Grafik 11: Profil MCHC pada wanita penderita sindrom koroner akut

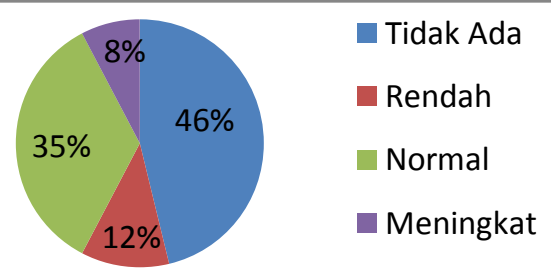

Grafik 13: Profil MCH pada pria penderita sindrom koroner akut

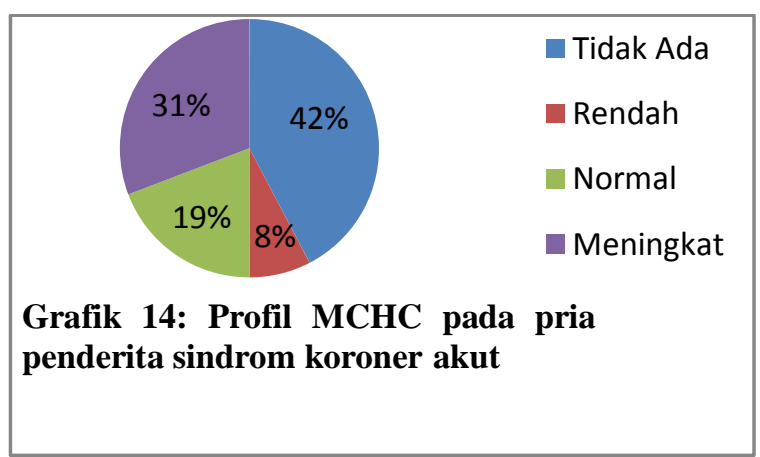

Berdasarkan standar yang diajukan Longo, hasil temuan pada MCV ditemukan total lima belas pasien memiliki kadar MCV normal, enam pasien memiliki kadar MCV rendah, dan delapan belas yang data hilang/tidak ada. Pada hasil temuan $\mathrm{MCH}$, total ada empat belas pasien dengan kadar $\mathrm{MCH}$ normal, lima pasien dengan kadar MCH yang rendah, dua pasien dengan peningkatan kadar $\mathrm{MCH}$ dan delapan belas yang data hilang/tidak ada. Untuk MCHC, ditemukan total ada sepuluh pasien dengan kadar MCHC normal, empat pasien dengan kadar MCHC yang rendah, dan delapan belas pasien dengan kadar MCHC yang meningkat. $^{14}$

Dengan adanya nilai MCV dan $\mathrm{MCH}$, kita bisa mengategorikan kedalam kelompok berdasarkan morfologik. Empat pasien memiliki anemia makrositer, sebelas pasien dengan normokromoik nomositer, dan lima pasien dengan hipokromik mikrositer. ${ }^{8,15}$

\section{KETERBATASAN PENELITIAN} penelitian:

Ada beberapa keterbatasan dalam

1. Tidak dibedakannya data antara pasien UAP, STEMI, NSTEMI dikarenakan tidak lengkapnya data hasil diagnosis pada rekam medis.

2. Tidak lengkapnya data hasil pemeriksaan pasien. Hal ini bisa dikarenakan tidak dilakukan pemeriksaan, data hilang, atau lainnya.

3. Minimnya jumlah sampel dan ini bisa diakibatkan oleh rekam medis yang tidak ada/hilang selama penyimpanan. 


\section{SIMPULAN DAN SARAN}

adalah:

Kesimpulan dari penelitian ini

1. Pasien sindrom koroner akut cenderung memiliki penurunan nilai hemoglobin.

2. Pasien sindrom koroner akut cenderung memiliki nilai leukosit yang normal.

3. Pasien sindrom koroner akut cenderung memiliki nilai trombosit yang normal.

4. Pasien sindrom koroner akut cenderung memiliki nilai hematokrit yang rendah.

5. Pasien sindrom koroner akut cenderung memiliki nilai MCV, MCH, dan MCHC yang normal.

6. Nilai hemoglobin bisa dijadikan dasar penilaian kegawatan dari penyakit pasien. Nilai leukosit yang meningkat disebabkan leukosit salah satu mediator inflamasi. Perubahan pada hasil pemeriksaan trombosit karena terlibatnya proses produksi trombus atau agregasi trombosit dan umumnya akan terjadi peningkatan. Nilai hematokrit, MCV, MCH, dan MCHC bisa dijadikan dasar untuk prognosis pasien.

Saran yang dapat diberikan dari penelitian ini adalah:

1. Untuk pihak rumah sakit lebih mengoptimalkan lagi tempat penyimpanan data pasien, dalam hal ini rekam medis.

2. Perlu diadakannya penelitan yang lebih spesifik dalam membahas hubungan hematologi pada sindrom koroner akut.

\section{DAFTAR PUSTAKA}

1. WHO. World Health Statistics. Perancis: WHO; 2012.

2. Burns D K, Kumar V. Penyakit jantung iskemik. Dalam: Kumar V, Cotran R S, Robbins S L, editor. Buku Ajar Patologi Edisi 7 Jilid 2. Jakarta: Penerbit Buku Kedokteran EGC; 2007: 408-16.

3. Trisnohadi H B. Angina pektoris tak stabil. Dalam: Sudoyo A W, et al, editor. Buku Ajar Ilmu Penyakit Dalam Edisi V Jilid 2. Jakarta: InternaPublishing; 2009: 1728-34.

4. Alwi I. Infark miokard akut dengan elevasi ST. Dalam: Sudoyo A W, et al, editor. Buku Ajar Ilmu Penyakit Dalam.
Edisi V Jilid 2. Jakarta: InternaPublishing; 2009: 1741-56

5. Harun S, Alwi I. Infark miokard akut tanpa elevasi ST. Dalam: Sudoyo A W, et al, editor. Buku Ajar Ilmu Penyakit Dalam Edisi V Jilid 2. Jakarta: InternaPublishing; 2009: 1757-66

6. Brown $\mathrm{C}$ T. Penyakit aterosklerotik koroner. Dalam : Price S A, Wilson L M, editor. Patofisiologi Konsep Klinis Proses-Proses Penyakit Edisi 6 Jilid 1. Jakarta: Penerbit Buku Kedokteran EGC; 2006: 576-612

7. Gray H H, Dawkins K D, Simpson I A, Morgan J M. Lecture Notes: Kardiologi Edisi 4. Jakarta: Penerbit Erlangga; 2005: 107-50.

8. Hoffbrand A V, Moss P A H, Pettit J E. Essential Haematology Edisi 5. Massachusetts: Blackwell Publishing, Inc.; 2006: 26.

9. Lipšic E, van der Horst I C C, Voors A A, van der Meer P, Nijsten M W N, van Gilst W H. Hemoglobin levels and 30-day mortality in patients after myocardial infarction. International Journal of Cardiology. 2005;100(2):289-92

10. Dharma S. Perspectives in the treatment of cardiovascular disease : from prognostic parameters to therapeutic modalities [dissertation]. Leiden: Universiteit Leiden; 2013.

11. Briggs C, Harrison P, Machin S J. In: Michelson A D, editors. Platelets. 2nd ed. California: Elsevier; 2007. p. 475-83

12. School of Health Sciences. Cardiology Teaching Package A Beginners Guide to Normal Heart Function, Sinus Rhythm \& Common Cardiac Arrhythmias: Platelet Aggregation. [cited 2014 Jan 15]. Available from: www.nottingham.ac.uk/nursing/practice/r esources/cardiology/acs/platelet.php

13. Paul L, Jeemon P, Hewitt J, McCallum L, Higgins P, Walters $M$. et al. Hematocrit Predicts Long-Term Mortality in a Nonlinear and Sex-Specific Manner in Hypertensive Adults. Hypertension. 2012;60:631-38.

14. Adamson J W, Longo D L. Anemia and polycythemia. Dalam : Fauci A S, Kasper D L, Longo D L, Braunwald E, Hauser S L, Jameson J L, editor. Harrison's Hematology and Oncology. New York: Them McGraw-Hill Companies; 2010: 921. 
15. Bakta I M. Pendekatan Terhadap Pasien Anemia. Dalam: Sudoyo A W, et al, editor. Buku Ajar Ilmu Penyakit Dalam
Edisi V Jilid 2. Jakarta: InternaPublishing; 2009: 1109-15. 